\title{
Origins and Consequences of Tripartite Efficacy Beliefs Within Elite Athlete Dyads
}

\author{
Ben Jackson, ${ }^{1}$ Peter Knapp, ${ }^{1}$ and Mark R. Beauchamp ${ }^{2}$ \\ ${ }^{1}$ University of Leeds and ${ }^{2}$ University of British Columbia
}

\begin{abstract}
Drawing from Lent and Lopez's (2002) "tripartite" model of relational efficacy, the overall purpose of this study was to examine antecedents and consequences of selfefficacy, other-efficacy, and relation-inferred self-efficacy (RISE) within six international-level athlete dyads. Semistructured interviews were conducted and data were content analyzed using deductive and inductive procedures. Sources of efficacy emerged in relation to perceptions regarding (i) oneself, (ii) one's partner, (iii) the dyad/relationship, and (iv) external factors. Results also revealed the emergence of a number of salient intrapersonal and interpersonal outcomes, incorporating cognitive, affective, as well as behavioral consequences. Implications for theory development and future research are considered, and applied propositions are discussed with regard to effective relationship management in elite sport.
\end{abstract}

Keywords: relational efficacy, content analysis, tripartite model

Within the sport psychology literature a considerable amount of research has focused on the nature and determinants of personal (or self-) efficacy beliefs (Bandura, 1997; Moritz, Feltz, Fahrbach, \& Mack, 2000). Self-efficacy appraisals refer to a set of beliefs in one's own capabilities to "organize and execute the courses of action required to produce given attainments" (Bandura, 1997, p. 3). However, it is rare that athletes in sport exist in social isolation, and they often train and perform with an array of significant others, such as a partner or coach, en route to achieving success. Recently, Lent and Lopez (2002) presented a conceptual model to illustrate how efficacy beliefs might manifest themselves within such interdependent settings, and how within close relationships, people not only develop beliefs about their own capabilities, but they also develop a set of efficacy cognitions related to these significant others. Relational efficacy beliefs, Lent and Lopez theorized, could in turn have substantive effects for individual as well as relationship functioning.

Jackson is now with the School of Sport Science, Exercise, and Health, University of Western Australia, Crawley, WA, Australia; Knapp is with the School of Healthcare, University of Leeds, Leeds, U.K.; Beauchamp is with the School of Human Kinetics, University of British Columbia, Vancouver, BC, Canada. 
The two forms of relational efficacy conceptualized by Lent and Lopez (2002) include other-efficacy and relation-inferred self-efficacy (RISE), which together with self-efficacy formed the basis of their "tripartite" model. Lent and Lopez conceptualized other-efficacy as an individual's beliefs in his or her partner's capabilities to perform particular tasks (i.e., "I am confident in my partner's ability to. ..."). RISE, on the other hand, represents an estimation of how confident one's partner is in oneself (i.e., "I believe that my partner is confident in my ability to. ..."). Both other-efficacy and RISE are theorized to be conceptually distinct from each other and from self-efficacy, although in accordance with the socialcognitive framework from which the tripartite model derives (cf. Bandura, 1986), the three efficacy constructs are theorized to be causally interrelated.

Bandura (1997) theorized that, in the pursuit of individual (i.e., independent) tasks, self-efficacy beliefs are determined by mastery achievements, verbal persuasion, vicarious influences, and physiological and emotional states. In dyadic (i.e., interdependent) settings, and as alluded to above, Lent and Lopez (2002) asserted that in addition to these principal sources, self-efficacy beliefs could also emerge from "intrarelationship" (i.e., relationship-specific) cognitions that develop through dyadic enactment, such as holding favorable RISE and otherefficacy perceptions. In developing their theoretical framework, Lent and Lopez drew from the work of Snyder and Stukas (1999) related to the emergence of interpersonal expectations, and theorized that other-efficacy beliefs likely stem from perceptions regarding one's partner, including his or her past achievements, comparisons drawn between current and former partners, as well as third-party information (e.g., comments from other friends, colleagues) regarding the partner. RISE estimations, on the other hand, were theorized to result from one's appraisal of the partner's performance feedback and behavior, the goals a partner sets for the dyad, the amount of support provided by the partner, and the activities the partner is willing to engage in, as well as his or her verbal and nonverbal communication.

Lent and Lopez (2002) also proposed that each of the tripartite efficacy beliefs influences salient outcomes, such as one's choice of, and reliance upon, a relationship partner, the activities one is willing to engage in with that partner, the type and amount of effort expended in joint activities, and one's intentions to persist in relationships. Recent research has provided preliminary support for the utility of the tripartite model within close relationships in sport. For example, Jackson, Beauchamp, and Knapp (2007) employed actor-partner interdependence models (cf. Kenny, Kashy, \& Cook, 2006) with youth tennis pairs, to examine the interrelationships among the three efficacy constructs, as well as their potential to predict relationship commitment and satisfaction. Jackson et al. found that otherefficacy and RISE were able to predict significant variance in athletes' self-efficacy beliefs. Furthermore, self-efficacy was found to be significantly related to one's own as well as one's partner's commitment to the relationship, and analyses also showed that other-efficacy was a significant predictor of one's own relationship satisfaction. In a separate study, conducted within the sport of equestrian eventing, Beauchamp and Whinton (2005) examined the relationships between riders' confidence in their own (self-efficacy) and their horses' capabilities (otherefficacy) and riding performances. Not only was other-efficacy found to be related 
to self-efficacy in this study but other- and self-efficacy were also found to be independently able to explain unique variance in riding performance.

Although these investigations provide preliminary insight into the consequences of holding various relational efficacy beliefs, research has yet to examine the origins (or antecedents) of efficacy beliefs within close relationships in sport. Thus, the primary purpose of this study was to examine the sources of self-efficacy, other-efficacy, and RISE within elite athlete dyads. International-level athlete dyads were selected for this study, primarily because in such settings members invest a considerable amount of time, effort, and personal resources in their partnerships. As such, relational beliefs are likely to be particularly salient. This investigation drew from a social constructionist perspective (Schwandt, 2000) to understand in athletes' own words (Creswell, 2003), the sources (or origins) of athletes' tripartite efficacy beliefs within dyadic settings. Social constructionism is grounded within a paradigmatic framework in which individuals develop their own subjective meanings, or "lived experiences," through their social interactions with others (for an excellent review of social constructionism, see Ponterotto, 2005). Specifically, this approach is concerned with understanding the manner in which people reflect on and interpret their own and others' behaviors, and the meanings and values that they ascribe to those interactions. Gergen and Gergen (2003) have noted that social constructionism is "concerned with explicating the processes by which people come to describe, explain, or . . . account for the world in which they live" (p. 15), and in so doing, participants are enabled to document their unique, subjective perceptions through the use of qualitative methodologies. Such an approach was believed to enable examination of athletes' efficacy beliefs with direct reference to Lent and Lopez's (2002) conceptual model (in particular with regard to the above-theorized antecedents), but also allowed for additional sources to emerge and be considered. Furthermore, as Strauss and Corbin (1998) suggest, qualitative approaches, such as those that accompany social constructionism "can be used to explore substantive areas about which little is known ... to gain novel understandings" (p. 11), as well as in instances where researchers aim to extract information regarding "the intricate details about phenomena such as feelings, thought processes, and emotions that are difficult to . . . learn about through more conventional research methods" (p. 11).

In light of the fact that researchers have also yet to examine outcomes associated with relational efficacy beliefs among athletes at the international level, the second purpose of the study was to examine consequences for elite athlete functioning connected with the tripartite efficacy beliefs. Again, a qualitative social constructionist approach was used to enable an examination of consequences congruent with the Lent and Lopez (2002) model, as well as those not conceptualized within their theoretical framework.

\section{Method}

\section{Participants}

Six international-level athlete partnerships (mean age $=27.8$ years, $S D=9.5$ ) were recruited from dyadic sports (synchronized swimming, synchronized diving, table tennis, pairs kayak, figure skating, sailing), representing one mixed-sex, 
three all-male, and two all-female relationships. As an indication of their "elite" status, all of the participants had competed at major championships, including the Olympics and world championships. Dyad members reported an average of 4 years of competing together $(S D=2.63)$, and the shortest relationship was 2 years. In addition, participants had, on average, 17.83 years of experience in their sport $(S D=9.17)$ and $14.17 \mathrm{hr}$ of training with their partner per week $(S D=6.25)$. To protect their anonymity, participants were coded from 1 to 6 according to their dyad, with each person randomly assigned as Person A or B (e.g., 1A, 1B). In addition, where meaning units are presented in the results, all names and identifying information have been removed to protect participants' identities.

\section{Procedures}

After obtaining permission to conduct the study from the Human Subjects Ethics Board at the lead investigator's institution, recruitment letters were posted to governing bodies of dyadic sports in the United Kingdom. Potential participants were informed that (a) participation was voluntary, (b) anonymity was ensured, (c) they could choose not to answer any questions if they wished, and (d) they could withdraw from the interview/study at any time. After obtaining their informed consent, interviews were subsequently arranged with participants at a time and place of their choosing. Discussions with dyad members were conducted separately on a one-to-one basis with the lead investigator and were audio-recorded, to allow for subsequent transcription. Upon completion of interviews, all participants were thanked for their time and were given the opportunity to ask questions on the nature of the investigation.

\section{Interview Guide}

The lead author conducted all interviews and had prior first-hand experience of open-ended interviewing in elite sporting contexts. Before data collection, guidelines from key qualitative texts were reviewed and the interview guide was piloted with two athlete dyads to assess the interview breadth and depth, as well as to highlight any problematic questions. The final semistructured interview guide consisted of five sections (available from the first author upon request) that comprised 12 broad questions designed to tap into the tripartite efficacy constructs. To orient participants to discuss their experiences of the focal constructs of this study, athletes were initially informed that the interview would focus upon different types of confidence that they may have experienced in their respective sports (the term confidence was used rather than self-efficacy to enhance participant understanding). In Section 1 of the interview, demographic data were obtained regarding the individual's experience in the sport, length of relationship, and amount of time spent with their partners each week. The subsequent three sections were designed to elicit information on antecedents and consequences of selfefficacy, other-efficacy, and RISE, respectively. Given that each of these efficacy constructs are theorized to be task-specific (Bandura, 1997; Lent \& Lopez, 2002), athletes were first asked to explain (and write down) the primary tasks required of themselves and of their partners in their respective sports. Exemplar tasks identified by athletes were diverse and included technical (e.g., performing a specific maneuver), relationship management (e.g., provide social support), psychological 
(e.g., remain calm under pressure), and physical (e.g., strength) skills. To further direct participants to discuss each of the tripartite beliefs, Sections 2-4 of the interview began with three key orientation questions. With regard to self-efficacy athletes were initially asked, "Could you describe your confidence in your own ability to carry out those skills listed"? In the section on other-efficacy, athletes were asked, "Could you describe your confidence in your partner's abilities to carry out those skills listed"? In the section on RISE, athletes were initially asked, "Could you describe how confident you think your partner is in your ability with respect to those skills listed"?

Following the orientation questions for each of the tripartite efficacy beliefs, athletes were subsequently asked to recall, using their own words (Creswell, 2003), some of the sources (i.e., antecedents) underpinning each form of efficacy, as well as the implications (i.e., consequences) of these cognitions. For example, in the self-efficacy section of the interview, participants were asked, "Could you explain what gives you this confidence?" (antecedents) and "Could you explain how your confidence in your ability affects you and your relationship?" (consequences). Where appropriate, probing and clarification cues were employed to ensure that the researchers did not "take for granted common sense assumptions and understandings" (Bogdan \& Taylor, 1984, p. 96). In Section 5, participants were invited to (a) ask any questions about the study, (b) supplement any information not covered within the previous four sections, and (c) provide feedback regarding the interview. Interviews lasted for $40 \mathrm{~min}$, on average.

\section{Data Analysis}

The data were initially analyzed deductively by the first author whereby meaning units related to the sources or consequences of the three focal efficacy constructs were classified according to the theoretical framework advanced by Lent and Lopez (2002). Meaning units essentially represent a phrase, sentence, or paragraph containing conceptually relevant information (Tesch, 1990). However, where meaning units did not "fit" within the a priori model, data were also grouped inductively by the first author into novel themes. Meaning units were isolated where athletes described a specific antecedent or outcome associated with selfefficacy, other-efficacy, or RISE. Themes were only created in instances when more than one athlete highlighted the prevalence of a particular meaning unit. This was done to provide an overall representation of the most prominent (i.e., frequent) themes, as identified by the athletes. Such an approach is consistent with recommendations by Miles and Huberman (1994) that researchers identify recurrent themes and "lay aside the more tenuous ones until other informants and observations give them better empirical grounding" (p. 70). Software-based content analysis, using the QSR NVIVO program, was employed to group meaning units into conceptually similar lower-order themes and higher-order categories (Berg, 2007) that reflected the antecedents and consequences of each efficacy construct. Data collection was terminated at the point of data saturation, representing the time at which no additional themes emerged from the data (Miles \& Huberman, 1990). Specifically, when analyzing transcripts from participants in the sixth dyad, it was apparent that all emergent meaning units were consistent 
with existing themes, and no novel themes were formed during examination of these athletes' transcripts.

\section{Establishing Trustworthiness}

In light of concerns regarding validity and reliability in qualitative research (cf. Biddle, Markland, Gilbourne, Chatzisarantis, \& Sparkes, 2001; Merrick, 1999), threats to trustworthiness in the current study were minimized via consultation with both peers and participants. Consistent with recommendations regarding testimonial validity (Stiles, 1993), that is, the participants' reflections on the accuracy of findings, two procedures were incorporated into analyses. First, transcripts were sent to participants, who were asked to confirm the accuracy of the written accounts, and were invited to edit these (supplement or remove information) where appropriate. Second, a summary of results was mailed to athletes, who were again invited to corroborate and, where appropriate, refute the "reality" of the emergent themes and models (cf. Lincoln \& Guba, 1985). As a result of this reflexive process, participants were able to (a) substantiate their previously reported stories and (b) locate their own experiences within the context of the collated data.

In addition, a process of peer review was employed (Krippendorff, 2004; Lincoln \& Guba, 1985) whereby the two coauthors of the study independently examined and coded all meaning units from four interviews according to (preliminary) lower-order antecedent themes. Specifically, the second and third authors were provided with a list of all meaning units along with the preliminary names of lower-order themes (including definitions) that had been developed by the lead investigator at the initial analysis stage. To complete the review of meaning units, coauthors were asked to independently assign each meaning unit to any theme, and if any problematic issues arose (e.g., regarding the assignment of meaning units to themes) these were identified for subsequent discussion. Initially, an average consensus rate of $81 \%$ was found across the three researchers. Subsequently, in instances of disagreement, ultimately consensus was achieved through a fourstep process. This involved continuous debate between investigators regarding (a) the names and definitions of lower-order themes, (b) intertheme distinctiveness, (c) intratheme similarity, and (d) higher-order category names and definitions. As a result, some themes were collapsed together to form a single group of meaning units, and in other cases themes that reflected more than one concept were subdivided to more accurately reflect participants' responses. By the close of this review process, complete consensus had been achieved on all meaning units, themes, and categories.

\section{Results}

In total, the 12 interviews produced 116 pages of 12-point, single-spaced, transcribed text, resulting in 195, 254, and 149 meaning units for self-efficacy, otherefficacy, and RISE, respectively. Emergent themes were grouped into categories, which were subsequently classified as either antecedents or consequences of each efficacy construct. All themes and categories are displayed in Tables 1-6, with accompanying exemplar meaning units and frequency counts. Including frequency 
counts enables insight into the more commonly occurring themes highlighted by athletes (Mays \& Pope, 1995), but it is worth noting that these are not included as a marker of the particular 'importance' of certain themes (cf. Nordin \& Cumming, 2005). Antecedents and consequences of each efficacy construct are also represented diagrammatically in Figures 1-3.

\section{Antecedents}

Four distinct higher-order categories emerged across the three efficacy constructs, containing themes that reflected perceptions regarding (i) oneself (e.g., past individual mastery experiences), (ii) one's partner (e.g., perceptions of one's partner's physiological state), (iii) the dyad (e.g., the dyad's mastery achievements), or (iv) external factors (e.g., equipment).

\section{Self-efficacy}

Sources of self-efficacy were underpinned by themes in all four categories; however, perceptions regarding oneself were most frequently cited (see Table 1). Three themes emerged for perceptions regarding the partner, a single group of meaning units related to the dyad was evident, and a further four themes were classified as external factors.

Perceptions Regarding Oneself. Past individual mastery achievements were most often identified as a contributor to self-efficacy perceptions in this category. That is, individuals reported confidence from past personal successes (see Table 1). Meaning units reflecting strength, injury, fatigue, body shape, pain, and/or anxiety in relation to one's self-efficacy were categorized under the theme physiological and emotional factors. For example, 2A highlighted that "you're not confident about the dives . . . if you're hurting."

Analyses also showed that athletes were more confident in their own ability as a result of their experience in the sport. For example, Athlete 4A attributed his self-efficacy to the number of years experience in his sport, commenting, "it's a confidence that has to be built up through time, and . . . just experience." The fourth perception to emerge regarding oneself reflected how a high level of confidence outside sport contributed to sport-specific self-efficacy. For example, 5A reported that "as you go through your life, hopefully you gain confidence, and for me, I suppose other things in your life going well puts you in position to be confident [in sport]."

The final source of self-efficacy that emerged in this category related to precompetition preparation. In this theme it was evident that self-efficacy stemmed from the amount of effort exerted in training as well as the number of hours spent preparing for competition. Meaning units showed that athletes rated self-efficacy more positively as a result of both the quantity (i.e., time devoted) and quality (i.e., effort exerted) of precompetition preparation. For example, 1A demonstrated how the time spent preparing was central to his self-efficacy: "when you've been practicing for 4, 5 hours every day . . y you're going to get the confidence."

Perceptions Regarding the Partner. The first antecedent theme in this category reflected the role of positive verbal persuasion that one receives from a partner in 


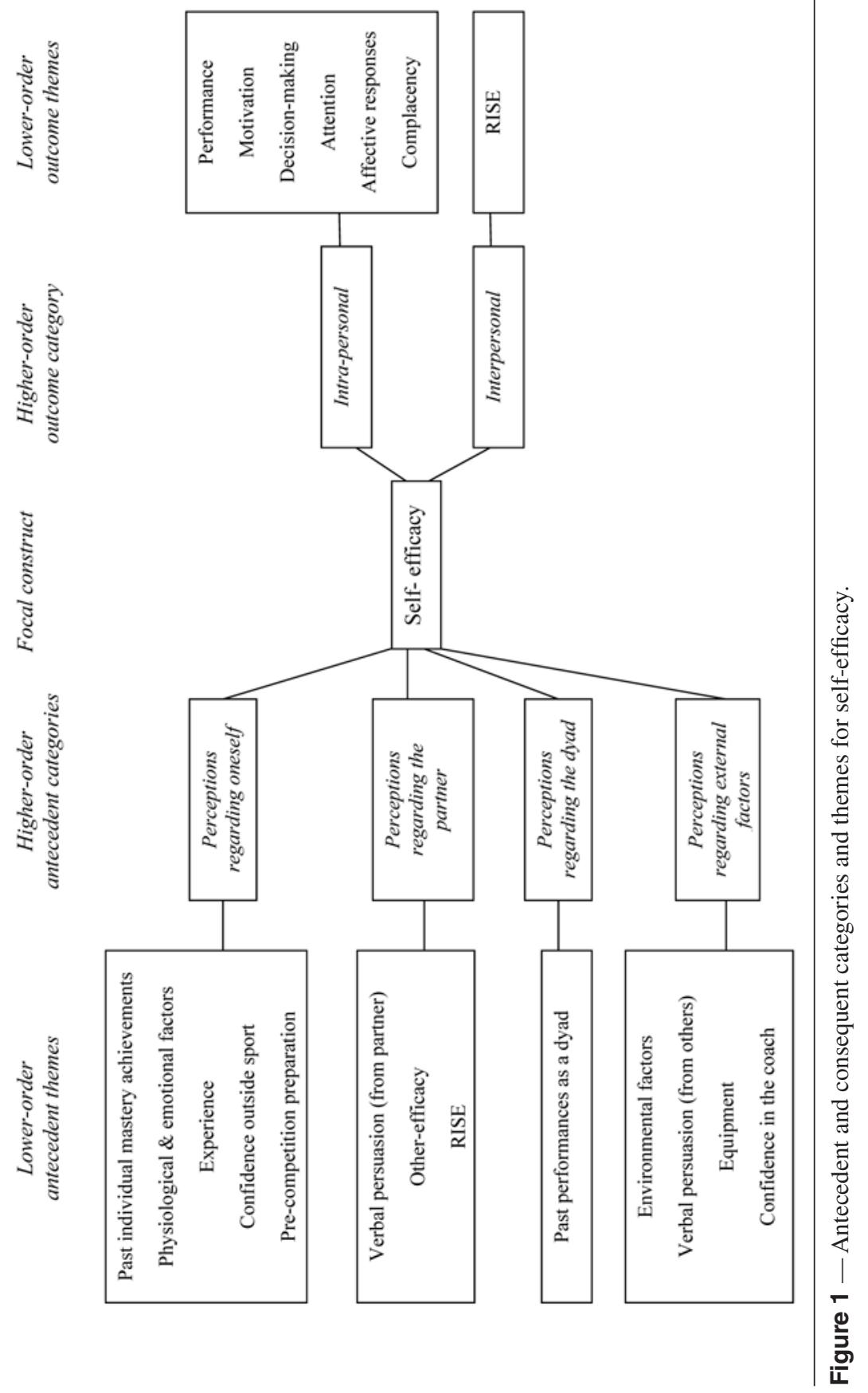




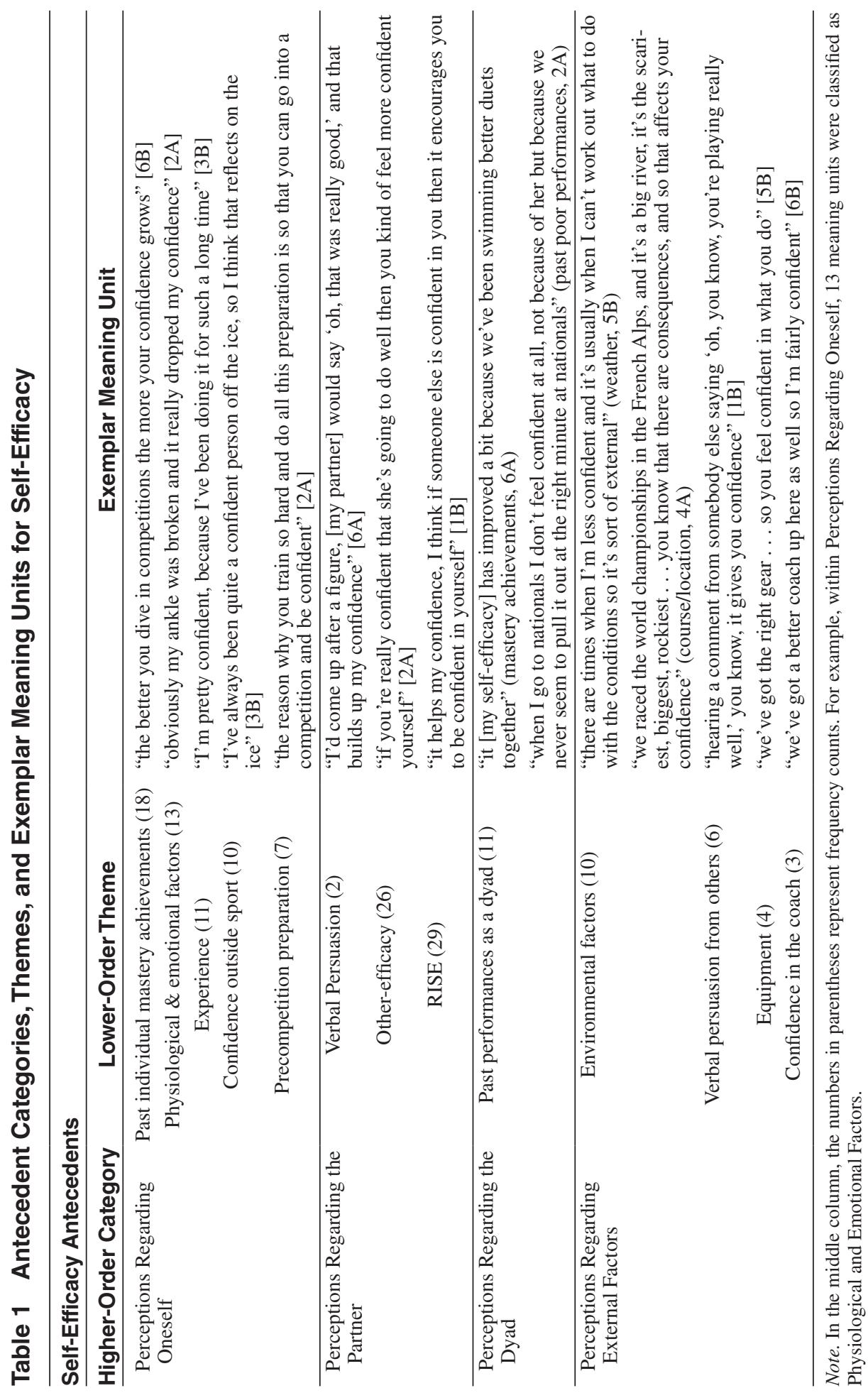


bolstering self-efficacy (see Table 1). The two other perceptions regarding the partner were indicative of the interrelated nature of the tripartite constructs. Specifically, athletes highlighted that they were more confident in their own ability as a result of favorable other-efficacy and RISE beliefs (these relationships with selfefficacy are also reflected in the intrapersonal consequences of other-efficacy and RISE in Tables 4 and 6, as well as Figures 2 and 3). For instance, in relation to other-efficacy, 1A described that "when you know what he's capable of . . . it lifts your self-confidence a bit." In addition, a number of athletes highlighted the impact of RISE upon self-efficacy beliefs, saying, "if you can see he's confident in you, then it helps your own confidence for sure" [1B].

Perceptions Regarding the Dyad. The sole theme in this category provided evidence that an individual's self-efficacy was not only underpinned by his or her past individual performances, but also by past performances as a dyad. This theme contained meaning units reflecting both mastery achievements (which enhanced self-efficacy) as well as past poor performances together (which diminished self-efficacy). For instance, in identifying the dyad's mastery achievements, 4B outlined that "we were going really well and the [self-]confidence was just there."

Perceptions Regarding External Factors. This category contained themes that did not refer to oneself, one's partner, or the dyad. For instance, it emerged that athletes who competed in outdoor sports (slalom kayak and sailing) reported weaker self-efficacy perceptions when competing during adverse weather conditions and/or at a particularly demanding course or location. These instances were coded as environmental factors (see Table 1). Other external sources of self-efficacy involved receiving verbal persuasion from individuals other than the partner. Athlete 2B demonstrated the impact of feedback from persons outside the dyad, reporting that "your . . . fellow divers, if you've done a dive, they'll come up and say 'yeah, that was really good'; that gives you a lot of confidence." The third theme in this category appeared to show that athletes were more confident in their ability when they had the optimal equipment (e.g., boat) for competition. Finally, a group of meaning units emerged that reflected enhanced self-efficacy as a result of one's level of confidence in the coach (i.e., other-efficacy, see Table 1).

\section{Other-Efficacy}

With respect to other-efficacy beliefs, seven antecedent themes emerged in relation to perceptions regarding the partner and two themes reflected perceptions regarding the dyad (see Table 2).

Perceptions Regarding the Partner. The first theme, partner's past performances, contained meaning units that reflected enhanced confidence in the partner's ability as a result of her or his past achievements, as well as decrements in other-efficacy stemming from past poor performances of the partner. For example, Athlete 2A emphasized the role of her partner's poor performances, noting that "if you see someone constantly messing up ... then you have to base your confidence in them on their performance and so it's not good." Third-party comments, on the other hand, reflected the receipt of positive feedback about one's partner from 


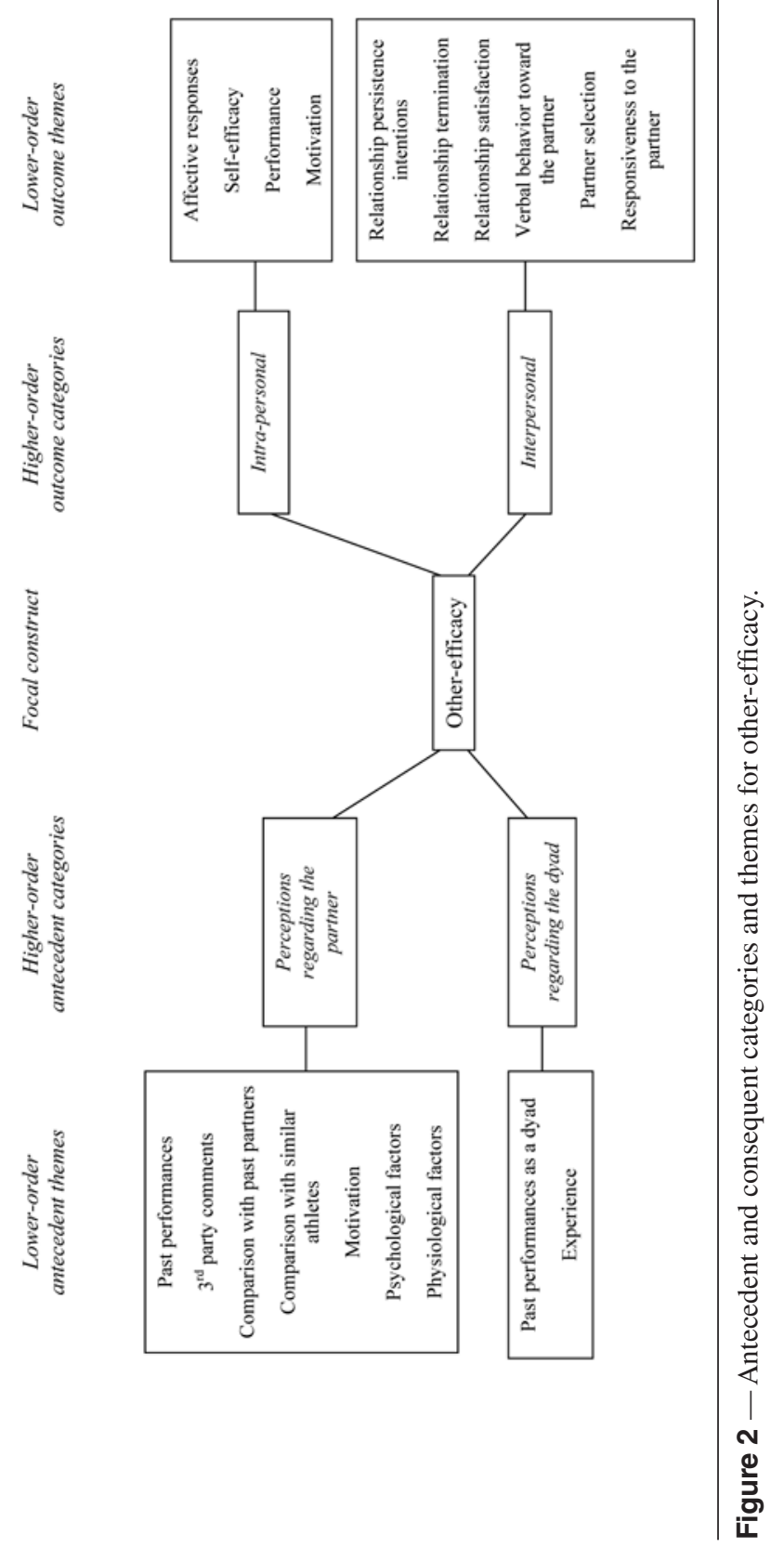




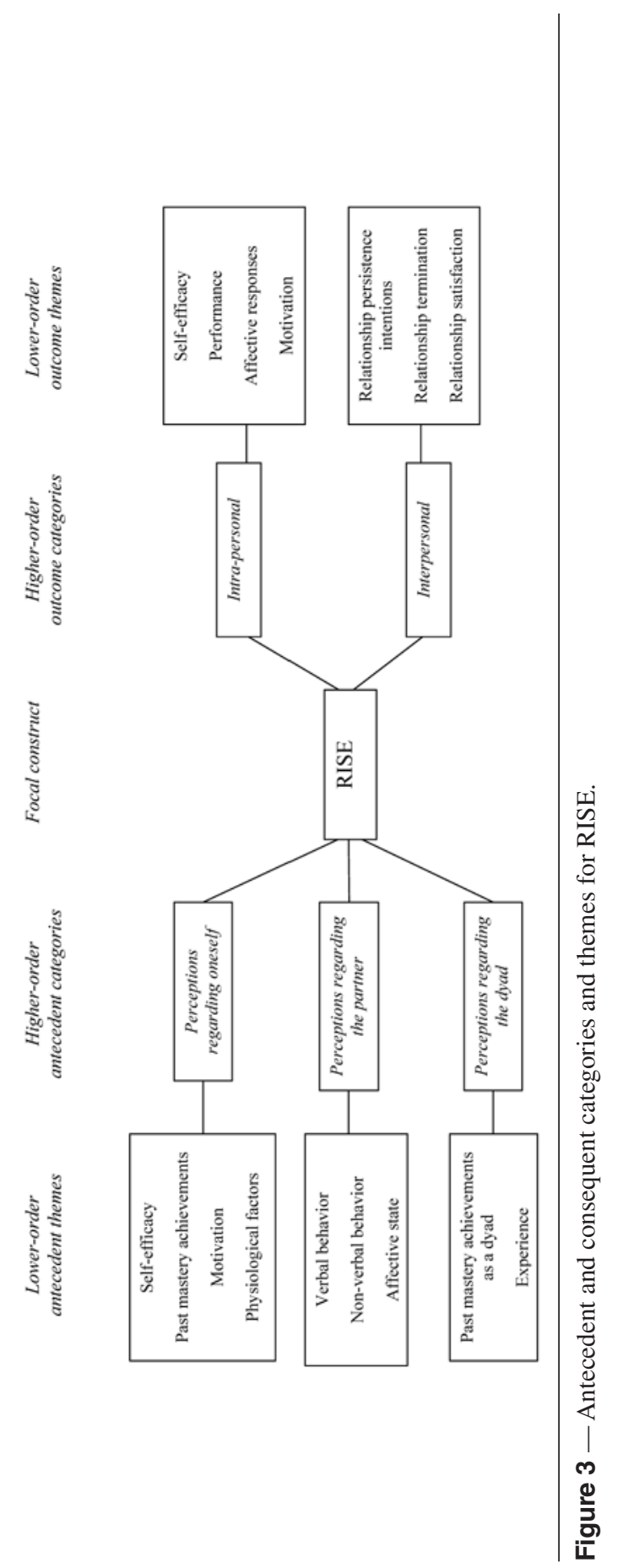




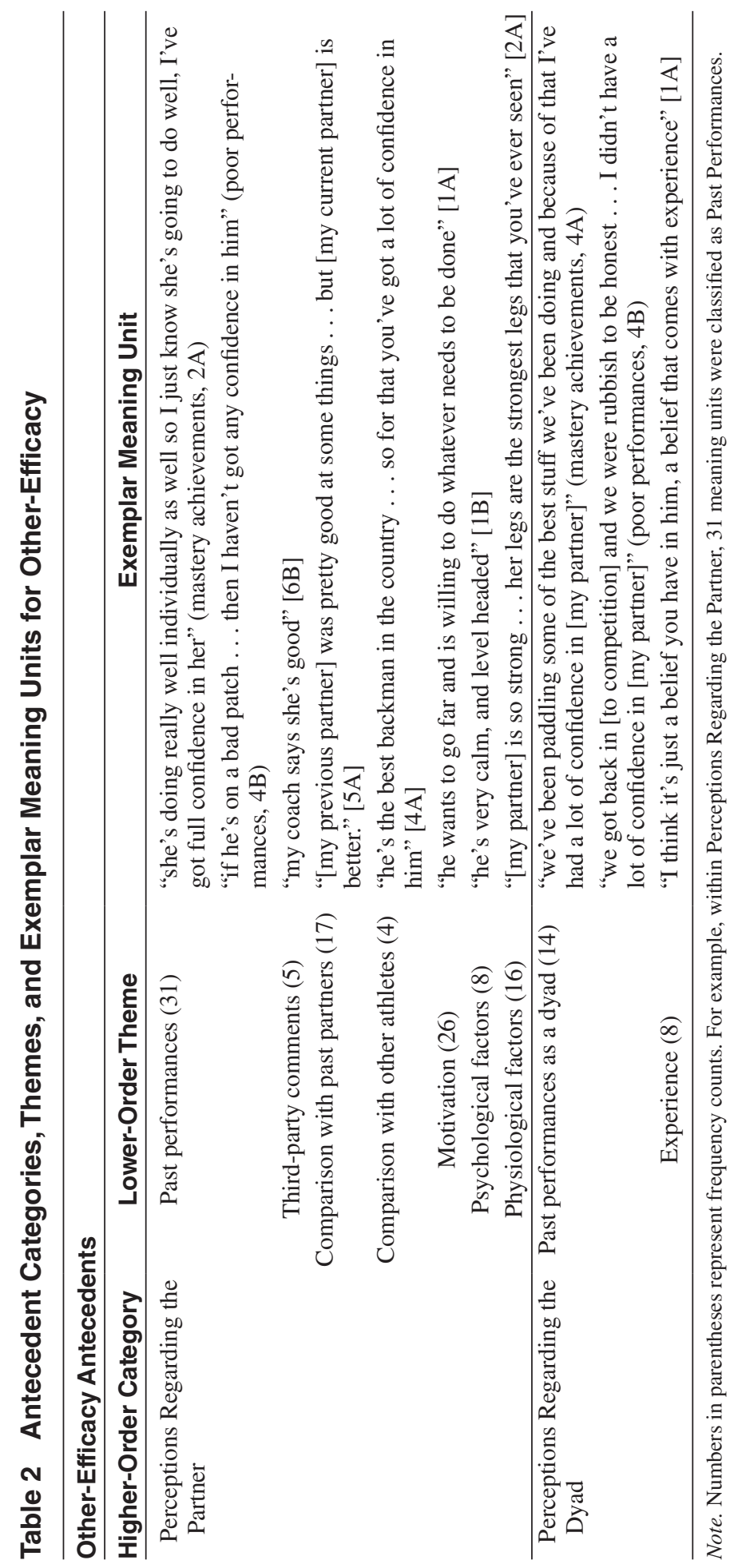


another person (e.g., coach), which were reported to have a beneficial effect on one's confidence in one's partner's capabilities. For example, 2A attributed her confidence in her partner to "people saying how well . . . she's diving."

The third and fourth themes were closely related, and reflected specific comparisons with past partners (e.g., "I prefer my [current partner's] attitude in the boat, it was a bit more erratic at times with my previous partner; [my current partner] tends to be . . . more consistent" [5B]), as well as comparisons with other athletes in general (e.g., "compared with others, he's just very good at all the stuff you have to do" [5A]). A number of specific partner characteristics also contributed to other-efficacy, namely, the partner's motivation, psychologicalfactors, and physiologicalfactors. Specifically, meaning units that reflected the partner's desire to succeed, achieve goals, continue competing, and comments that implied a willingness to work hard and determination were coded under motivation (see Table 2). Parenthetically, 4A outlined how a lack of motivation from the partner could influence other-efficacy, commenting, "I lose a little bit of confidence in him because I think, "well, is he searching for more . . . or not?",

A number of meaning units also showed that individuals were more confident in their partner as a result of the partner being "calm," "level-headed," "mentally strong," and "relaxed," which were coded as psychological factors (see Table 2). For instance, when questioned as to why he was confident in his partner, 5B mentioned that "he's just mister cool and relaxed really; he's great in that respect." Conversely, 4B attributed decrements in other-efficacy to his partner's inferior psychological characteristics, saying that "mentally he sometimes isn't as strong to hold it together." Finally, the partner's strength, physical condition, fatigue, and injury status were grouped as physiological factors. For example, Athlete 4B had reservations regarding his partner's capability, which stemmed from his perception that "one of [my partner's] disadvantages is that he seems to get injured a fair bit."

Perceptions Regarding the Dyad. In this category it emerged that past performances as a dyad contributed to other-efficacy beliefs. This theme incorporated both mastery achievements, which were associated with enhanced confidence in one's partner, as well as poor performances, which were related to diminished other-efficacy beliefs (see Table 2). Analysis also revealed that athletes highlighted that their experience as a dyad underpinned other-efficacy perceptions. This theme reflected a greater level of confidence in the partner's ability as a result of competing together for a number of years. This was illustrated by 6A, who mentioned, "we've been working together for quite a while and it's become a lot stronger since we've been working together a lot more over the years."

\section{RISE}

Antecedent themes emerged for RISE beliefs, that incorporated perceptions regarding oneself (four themes), one's partner (three themes), and the dyad (two themes). These are illustrated in Table 3 and Figure 3.

Perceptions Regarding Oneself. A number of themes reflected instances in which individuals used their own self-perceptions to determine metaperceptions (i.e., estimating the partner's cognition), whereby the partner was believed to see 


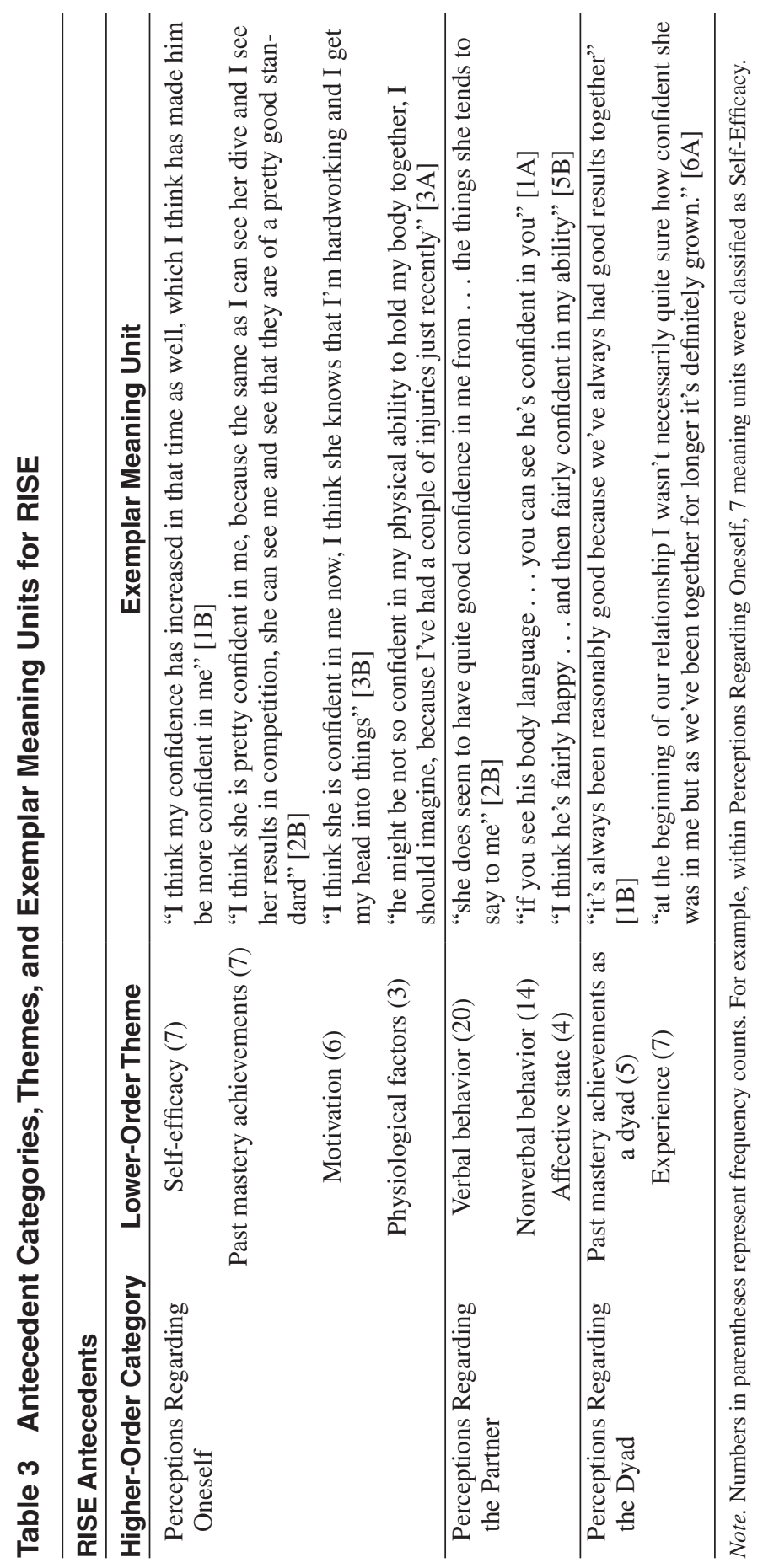


the individual in the same way that he or she saw him- or herself. Specifically, analyses revealed that one's own self-efficacy, past mastery achievements, motivation, and physiological factors were used when estimating how confident one's partner would be in oneself.

Athlete 3B illustrated how his own self-efficacy was used as a source of RISE appraisals (this relationship is also documented in the interpersonal consequences of self-efficacy, Table 4 and Figure 1), saying that, "I think it's grown especially in the last year, since my confidence in my skating's grown then I think hers has grown with it." Athlete 4B highlighted that his own past mastery achievements contributed to RISE perceptions, stating, "I'd say he's pretty confident in me because I'm quite reliable-do you know what I mean? and . . . I can pretty much always perform." Consistent with the content of other motivation themes, individuals cited their own level of determination, desire, effort, and drive to succeed as factors likely to influence the partner's confidence in their ability (i.e., RISE, see Table 3). For example, 4A felt that, "because he knew I was doing my best, I think there's a good level of confidence in me." Finally, athletes outlined how their own physiological factors, including fatigue, injury status, and fitness level, also influenced RISE appraisals. Athlete 4B added, "sometimes I get days when I'm tired or not quite with it and then . . . he doesn't have that confidence [in me] on that day."

Perceptions Regarding the Partner. Within this category, the partner's verbal behavior emerged most frequently as a source of RISE, referring to the content and frequency of partner feedback, as well as how the partner conveyed messages. Athlete 6A pointed out how messages with supportive content contributed to RISE: "she had a lot of confidence in me ... she was saying "you can do it, I know you can do it." "Furthermore, 3B highlighted that infrequent verbal feedback from the partner can lead to unfavorable RISE beliefs, stating that "when somebody goes quiet or they try not to mention things to you, then you know." In addition to the content and frequency of feedback, 4B emphasized how RISE was underpinned by the way in which feedback was given, citing that "if we get to the bottom of a run . . . you can just tell in the way he talks - do you know what I mean?- - things he says but the way he says them as well, I suppose [emphasis added]." Athlete 5B concurred, "I don't think he's ever raised his voice to me in two years really ... we've got confidence in each other's ability, really."

Results also showed that the partner's nonverbal behavior, including body language, was a source of RISE (see Table 3). As one athlete highlighted, "I just have to look at [my partner] and I can tell when he's got a concern or when his confidence has maybe dropped a fraction in me. I can tell; it's just the way that he looks; I can see [1A]." The final perception regarding the partner represented appraisals based upon the partner's affective state. Specifically, it emerged that if one believed the partner was displaying "happiness" and "enjoyment" during training and competition, athletes inferred favorable RISE beliefs.

Perceptions Regarding the Dyad. The first of two themes in this category illustrated that past mastery achievements as a dyad contributed to one's RISE estimation. For instance, 1B felt that his partner's confidence in him had "probably built over time as we've had good results together." In addition, greater experience as a dyad was also associated with enhanced RISE perceptions (see Table 3). 


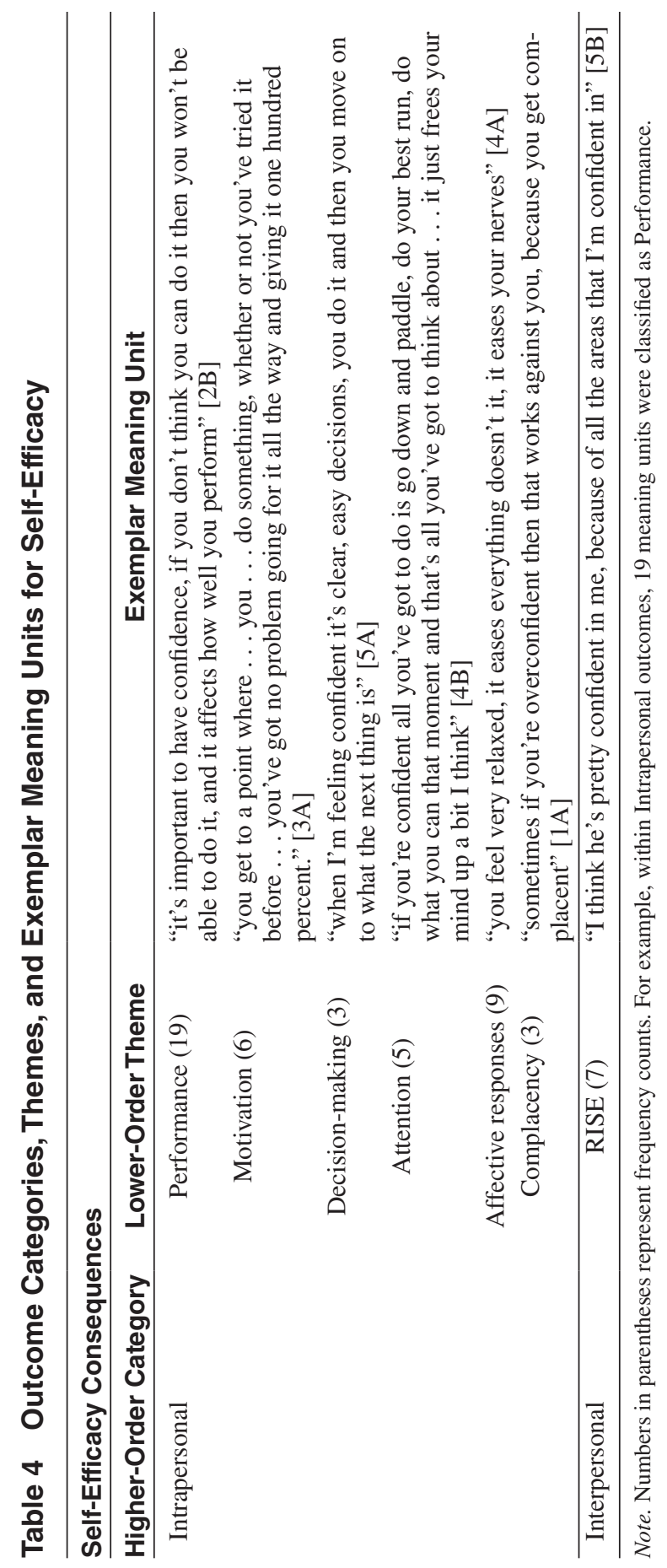




\section{Consequences}

Self-efficacy, other-efficacy, and RISE were associated with a number of important cognitive, affective, and behavioral consequences for elite athletes. Examination of outcome themes revealed a distinction between those that related to "intrapersonal" concepts (e.g., one's personal performance level, one's own motivation) and those that reflected perceptions, feelings, and behaviors regarding "interpersonal" concepts (i.e., themes that related to one's partner or the dyad). Categories and themes are subsequently presented separately for each construct.

\section{Self-efficacy}

It emerged that self-efficacy beliefs yielded six distinct intrapersonal outcomes, as well as one interpersonal theme (Table 4, Figure 1).

Intrapersonal. The most frequently cited theme related to the beneficial effect of self-efficacy in relation to one's own performance. One's confidence in one's own ability was also reported to be associated with personal motivation, characterized by greater levels of effort, desire, drive, and determination during training and competition (see Table 4). The third intrapersonal outcome illustrated that athletes' self-efficacy beliefs were associated with decision-making capabilities. Indeed, 5A commented that the decision-making process was made easier when he felt more confident in his ability, "if I'm confident then . . . I'll make tactical calls." Conversely, 5A also reported that "the times when I'm less confident it'll be, 'um, ah, well I'm not sure.'" The fourth theme, attention, reflected that greater levels of self-efficacy were related to one's ability to concentrate and direct attention to appropriate task-related aspects of competition. For instance, when 4A experienced diminished self-efficacy beliefs he reported that he was prone to "kind of sometimes losing a bit of concentration."

Athletes also identified decreased nerves, stress, worry, pressure, and enhanced happiness as a result of elevated self-efficacy perceptions, which were grouped as affective responses. For instance, 6B commented, "I don't tend to get stressed, I don't tend to get really upset" as a result of her confidence. Finally, in some instances, overestimating one's capabilities was linked to perceptions of complacency. This was evident in a quote by $1 \mathrm{~A}$, who said that "being confident is good . . . but sometimes you get overconfident and you step over the line and you try to do stuff that you wouldn't normally do."

Interpersonal. The single interpersonal consequence associated with self-efficacy showed that when athletes were highly confident in their own ability, this was associated with favorable RISE perceptions. That is, individuals reported that they felt their partner would be highly confident in their ability, as a result of their positive self-efficacy beliefs. For example, athlete 3B commented, "by being confident and not having any worries, then she can get that confidence in me."

\section{Other-Efficacy}

Other-efficacy perceptions were associated with a number of intrapersonal and interpersonal outcomes, as shown in Table 5 and Figure 2. Specifically, the 10 
outcome themes that emerged in relation to other-efficacy represented 4 intrapersonal and 6 interpersonal consequences.

Intrapersonal. The most frequently cited theme in this category was the effect of other-efficacy in relation to athletes' affective responses, which contained two distinct groups of meaning units. The first and most common type reflected desirable affective responses (i.e., enhanced relaxation and happiness, reduced stress, worry, and/or pressure) as a result of positive other-efficacy beliefs. It is worth noting that these affective responses did not focus upon one's feelings about the relationship; rather, they related to the individual's general affective state (see Table 5). For example, as a result of favorable other-efficacy beliefs, 4A felt that "you don't feel as much individual stress" when confident in the partner's ability. The second group of meaning units reflected negative affective responses that resulted from a high degree of confidence in one's partner's ability. For example, this was illustrated by 4B, who noted that "when we started I was always worried that I was going to make a mistake and let [my partner] down . . . because I'm a bit younger than [him] and he was a bit more experienced."

Analysis also showed that other-efficacy beliefs were positively related to one's self-efficacy. For example, athlete 6B voiced that, "when I thought I was working with weaker partners I think I was less confident." In addition, otherefficacy was reported to be associated with one's own performance. To illustrate, 5B noted, "I think it would be very hard to perform as well as I'd like to perform without full confidence in my partner." The final intrapersonal consequence of other-efficacy was termed motivation, as described by $2 \mathrm{~A}$, who noted that, "you try so hard, to be honest, if you're with someone who you think is . . really, really good." On the contrary, 4A underlined potential amotivation that may result from low levels of other-efficacy, saying that, "you haven't got confidence in them, and it's like, what am I doing wasting my life?"

Interpersonal. The first theme, relationship persistence intentions, represented a cognitive implication associated with other-efficacy, containing meaning units reflecting the individual's desire to persist in the relationship. Specifically, it was evident that those who were highly confident in their partner's capabilities wanted to persist in the relationship (e.g., "if you've got confidence in him you want to do it again" [5A]), whereas those who held lowered other-efficacy beliefs did not wish to continue as a dyad (e.g., "if you're not confident in your partner's ability then ... whenever you have the option you would choose not to be with them" [1B]).

Relationship termination reflected a behavioral outcome of other-efficacy. The majority of meaning units in this theme indicated that the relationship would "break down" if an individual was not confident in his or her partner's ability. For example, 3B felt that "eventually when things get harder ... if you don't have that confidence in that person then things are not going to work." Interestingly, a separate group of meaning units in this theme also highlighted that relationships may also break down as a result of positive other-efficacy beliefs. For example, one athlete commented, "I don't think me and [my partner] are necessarily suited to competing together, because ... she's got the natural talent to take her dives to a harder level than I possibly can [2A]." The third interpersonal theme illustrated the effect of other-efficacy in relation to one's relationship satisfaction. That is, 


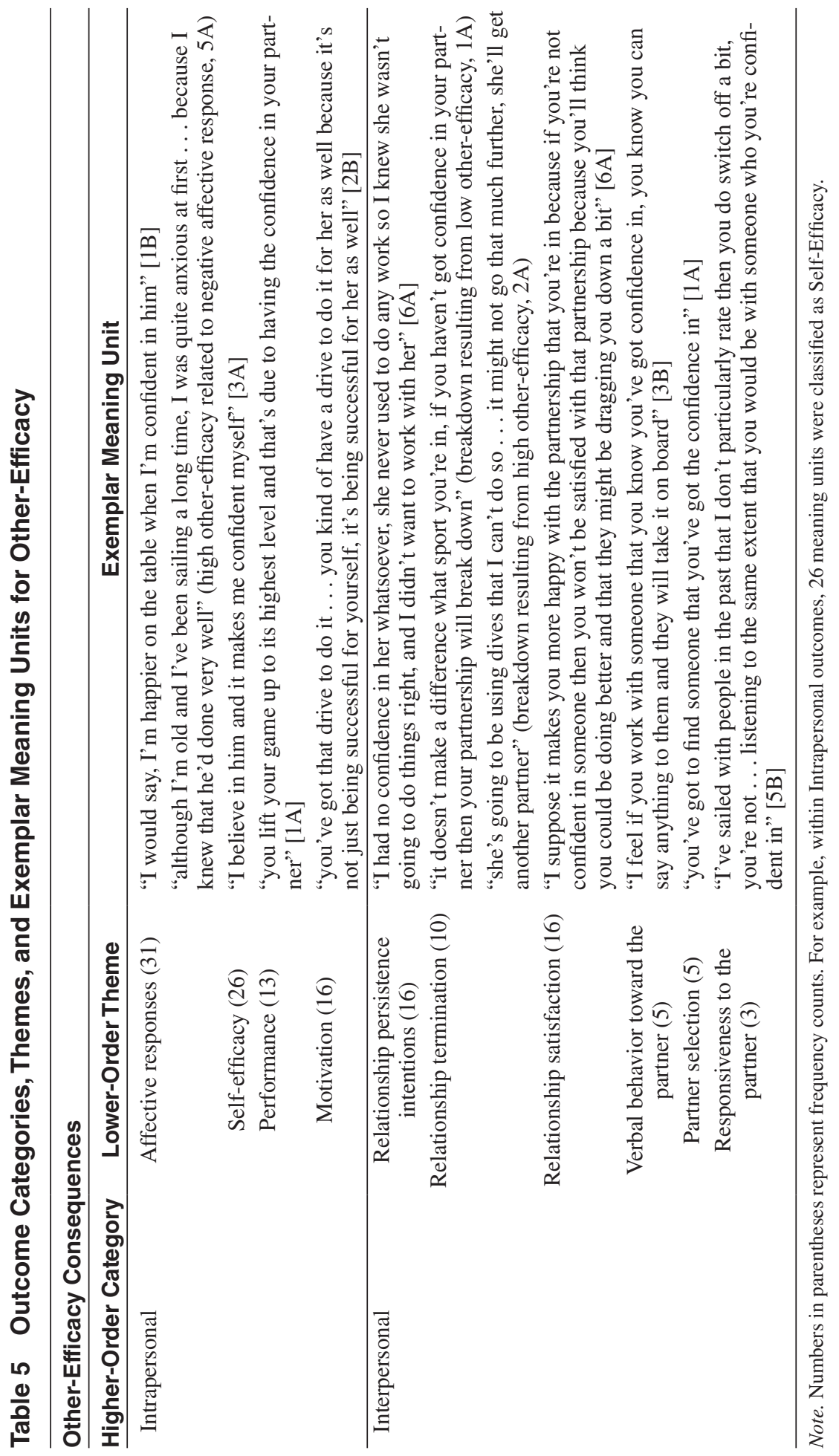


individuals appeared to display greater enjoyment and satisfaction with their relationship when describing positive other-efficacy (See Table 5). Note that relationship satisfaction refers specifically to feelings about the relationship, rather than general affective responses, which were categorized under intrapersonal consequences.

The fourth theme in this category highlighted the implications of other-efficacy in relation to one's verbal behavior toward the partner. Individuals who were highly confident in their partner's ability provided positive verbal feedback to the partner (e.g., encouraging, complimenting the partner on her or his performance, see Table 5). For instance, as a result of positive other-efficacy beliefs, 4B described his complimentary feedback to his partner: "I'll always say at the bottom of that run, or whatever, I'll say 'that was a beauty, that stroke you did there."'

The penultimate theme, partner selection, referred to choices made during the pre-relationship phase of interaction, whereby participants highlighted that they would only initiate a relationship with someone about whom they held positive other-efficacy beliefs. Athlete 4A felt that, "[my partner] is the best in this country at what he does - there's no one, there's no one else that I would choose ahead of him." The final interpersonal theme was termed responsiveness to the partner, reflecting that individuals were more likely to accept a partner's decision, as well as to listen to and act upon the partner's advice, as a result of being confident in his or her capabilities. For example, 5A outlined that, "we come to that crossroad occasionally, where I don't know what to do and [my partner] will just say 'let's just do this' . . . and I'm happy with that and I take that."

\section{RISE}

Athletes identified a total of four intrapersonal as well as three interpersonal consequences in relation to RISE beliefs (see Table 6 and Figure 3).

Intrapersonal. The most frequently cited intrapersonal consequence reflected the effect of RISE in relation to self-efficacy beliefs. When discussing RISE, one athlete mentioned, "if you feel that your partner's not confident in you, then you lose confidence [1A]." Interestingly, also contained in this theme were meaning units that stressed the role of RISE during periods of self-doubt, when self-efficacy beliefs were particularly low. For instance, 2B discussed this buffering effect, recalling that, "if you're not quite so confident about something, then it's good to have someone confident in you who will maybe help your confidence." The second intrapersonal theme demonstrated that RISE beliefs were positively related to one's own performance. For example, 6B recalled, "I did a competition a couple of years ago and I was about 17 and my partner at that time ... really wasn't confident in my ability whatsoever, and I swam very . . . aggressively . . . and it definitely affected my performance."

Affective responses also emerged in relation to RISE. For example, while outlining the implications of negative RISE estimations, 1A said, "I don't think there's anything more ... frustrating", and 2B added, "it's not much fun . . . if you don't think the person you're diving with . . . has confidence in you." Similarly, 6A felt that low RISE beliefs "would make me feel upset . . . and I'd . . . just sit there all miserable at the competition." Finally, it emerged that positive RISE estimations were predominantly related to enhanced levels of motivation, and that low 


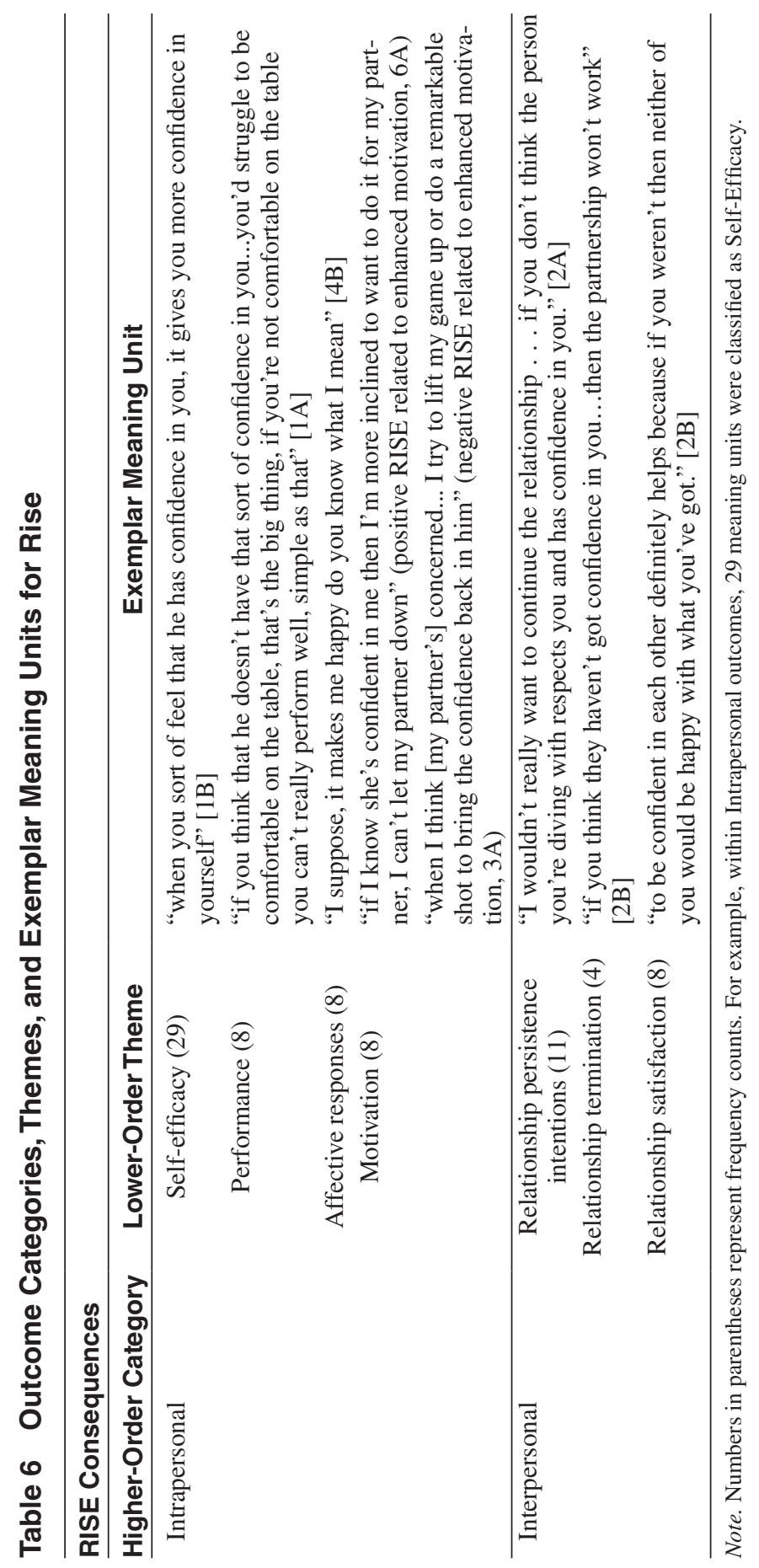


RISE perceptions were associated with diminished motivation. For instance, 3B noted that low RISE beliefs may result in amotivation, saying, "they don't think I can do it so why am I even bothering." However, a minority of meaning units in the motivation theme actually reflected increased motivation in response to low RISE beliefs. Indeed, the following quote suggests that an athlete's affective state might moderate his or her response to low RISE beliefs: "I think [low RISE] can work in two ways, [and] it depends on the mood I'm in, like, if I had a guy that didn't believe in me, I could . . . just go, 'actually, I'm going to prove to you that I can do it $[3 \mathrm{~A}] ., "$

Interpersonal. The most common interpersonal theme highlighted the relationship between RISE beliefs and relationship persistence intentions (see Table 6), insofar as individuals intended to persist with partners that were estimated to be confident in their ability (i.e., positive RISE beliefs). For example, 2A noted, "I think because she's confident in me that makes me want to carry on."

RISE was also associated with relationship termination, whereby low RISE estimations accompanied the breakdown (or forecasted breakdown) of the relationship. For example, 3B highlighted that "if someone doesn't have that belief in you mentally, you know you can't sort of progress as a great partnership . . . and it's like any relationship, it's going to break down eventually." Finally, analysis revealed that enhanced RISE beliefs were associated with relationship satisfaction. Again, this theme contained meaning units that pertained directly to feelings about the relationship, rather than general affective responses. This was evident in a comment from $3 \mathrm{~A}$, who said, "because we . . . believe in each other then it's always a joy to come in and actually work with someone like that."

\section{Discussion}

In their seminal paper, Lent and Lopez (2002) theorized that "in close relationships, partners help to mutually construct, validate, and preserve (or revise) their self views via their relationship behavior" (p. 261). Indeed, as people form and develop close social relationships, they invariably access different sources of efficacy information that are grounded within the unique contexts of these relationships. The results of this study provide support for the existence of relational efficacy sources and consequences that are consistent with those outlined within the tripartite model, but also identify potential antecedents and outcomes beyond those initially conceptualized by Lent and Lopez.

In accordance with theorizing by Bandura (1997), as well as Lent and Lopez (2002), self-efficacy was reported by athletes to stem from factors such as past individual and dyad achievements, physiological and emotional factors, verbal persuasion, and experience, as well as the two intrarelationship cognitions of other-efficacy and RISE. Interestingly, sport-specific self-efficacy was also reported to be bolstered by a general sense of confidence outside sport. Bandura refers to this as a generality effect, and the findings from this study appear to substantiate the conclusion of Chase, Feltz, and Lirgg (2003) that outside sources, including confidence in general life contexts, may contribute to athletes' sportspecific self-efficacy. Chase et al. also highlighted precompetition preparation as a source of personal efficacy, which similarly emerged as an antecedent theme 
within this study. Greater time and effort devoted to practice provides greater opportunities for personal mastery and thereby likely augments one's personal sense of capability. The final source of self-efficacy to emerge related to environmental factors (e.g., weather, course). This finding is consistent with theorizing by Bandura insofar as the strength of oneself-efficacy beliefs can be affected by the level at which they are rated. That is, as required threat levels substantively increase owing to adverse weather or course conditions, personal capability beliefs become acutely tested and may even diminish.

The sources of other-efficacy that emerged in this study were largely congruent with those theorized by Lent and Lopez (2002) and included the duration of experience with a partner, the partner's and dyad's past mastery performances, third-party comments, and comparisons with past partners and other athletes. Beyond these, a number of novel sources also emerged. It is noteworthy that Snyder and Stukas (1999) and Bonito (2002) suggested that interpersonal expectations may stem from certain characteristics of the target. In this study, the partner's perceived motivation, psychological factors (viewed as "calm," "levelheaded," "relaxed"), as well as physiological characteristics (e.g., strength) were reported as additional sources of athletes' confidence in their partners (other-efficacy). Although they did not use an efficacy framework, it is noteworthy that Wickwire, Bloom, and Loughead (2004) comparably concluded that within elite dyadic settings it is important for athletes to have partners that are motivated and psychologically strong. With regard to the physiological characteristics of the partner, a number of authors have suggested that individuals derive their expectations of others based on physical stereotypes (e.g., Lubker, Watson, Visek, \& Geer, 2005; Snyder \& Stukas, 1999), and in this study it was notable that athletes appeared to judge their confidence in their partner based on the apparent physical appearance and conditioning of that person (e.g., athletic, muscular).

The final efficacy construct, RISE, was reported to arise from one's own selfefficacy beliefs, as well as one's partner's verbal and nonverbal behavior, and affective states. Each of these sources were identified by Lent and Lopez (2002). However, beyond these, a number of additional "perceptions regarding oneself" also emerged as sources of RISE, including one's own motivation, past mastery achievements, and physiological factors. There is evidence for this phenomenon, whereby metaperceptions are believed to reflect self-perceptions, a process which is often referred to as assumed similarity (Kenny \& Acitelli, 2001). Kenny and Acitelli outlined that, when assuming similarity, "The partner of the perceiver is assumed to see things the same way as the perceiver does" (p. 441). So, for instance, if an individual's poor physiological condition resulted in low self-efficacy, this may also undermine RISE beliefs.

The second purpose of our study was to ascertain the consequences associated with the tripartite efficacy constructs. For self-efficacy, the consequences that emerged were largely consistent with theorizing by Bandura (1997) and Lent and Lopez (2002) and included improved affect, elevated individual performance, and greater effort/motivation (all of which also emerged as consequences across both other-efficacy and RISE perceptions). In addition, self-efficacy was reported to enable athletes to concentrate and direct attention to appropriate task-related aspects of performance. In a similar regard, Bandura noted that "it requires a strong sense of efficacy to remain fully task oriented in the face of . . pressing 
situational demands" (p. 117). With particular relevance for interdependent contexts, athletes also reported that elevated levels of self-efficacy enabled (or empowered) them to engage in decision-making processes within their partnerships and take on tactical responsibilities. This is consistent with research that suggests that individuals with a strong degree of confidence tend to require less use of information-processing resources when performing given tasks (Chaiken, Liberman, \& Eagly, 1989).

Although the outcomes to arise from elevated self-efficacy were largely favorable, it is worth noting that the elite athletes in this study also reported the potential for complacency to emerge from supreme levels of confidence. Bandura (1982) has discussed the overestimation of capability (i.e., overconfidence) at length, whereby individuals may "feel little need to invest much preparatory effort" (p. 123), and it would seem logical to suggest that any such overconfidence would not only compromise the athlete's ability to function (via diminished effort and motivation), but would also debilitate the partner's ability to effectively interact with him or her.

In close relationships, Snyder and Stukas (1999) theorized that individuals typically hold inclusionary orientations in response to favorable perceptions about a partner (i.e., positive other-efficacy), such as to the desire to maintain interactions and maximize contact with the partner. Mirroring Lent and Lopez's (2002) assertions regarding the implications of other-efficacy, inclusionary orientations appeared to manifest themselves across interpersonal consequences in this study. For instance, one's confidence in one's partner's ability was associated with more open and positive verbal behavior toward the partner, greater responsiveness to the partner, and enhanced relationship satisfaction and persistence intentions. Conversely, where negative partner expectations exist, Snyder and Stukas proposed that individuals would adopt exclusionary orientations (e.g., negative perceptions about the partner, and exclusion from dyadic interaction). This was apparent where athletes in this study reported that, as a result of diminished otherefficacy, they were unsatisfied, unlikely to persist in the relationship, could not provide encouragement to the partner, and felt the relationship would likely break down.

Although other-efficacy was largely found to be related to positive and prosocial (e.g., responsiveness to one's partner) outcomes, it is particularly interesting that some athletes also forecasted that elevated levels of other-efficacy might be related to potential negative affective responses, and even the possible breakdown of their relationships. This finding was somewhat unexpected, and was not discussed by Lent and Lopez (2002); however, this does appear to be consistent with Bonito's (2002) notion that individuals may experience negative responses as a result of others' successes through a process of interpersonal comparison. Although the mechanisms underlying these responses clearly require further investigation, it is possible that discordance between one's beliefs in one's own capabilities (self-efficacy) and beliefs in one's partner's capabilities (other-efficacy) may be responsible for negative affect and projected relationship termination. Interestingly, Lent and Lopez advocated that the extent to which self- and other-efficacy "are harmonious and complementary with one another may have important implications for each individual" (p. 276). The flip side, however, is that if an athlete has more confidence in the partner (other-efficacy) than she or he has 
in her- or himself, then this may bring about impaired affect and an expectation that the partner will likely leave for another partner.

Understanding how people appraise what others think of them (i.e., metaperceptions) represents a fundamental question within social cognition research. In this study, elite athletes' appraisals of their partners' confidence in them (RISE) were found to be associated with a number of important consequences. Of particular importance, RISE was identified by the athletes as being an important source of their own self-efficacy beliefs. Lent and Lopez (2002) theorized that RISE can act as a potentially important determinant of personal efficacy when "one possesses meager or discrepant self-efficacy information" (p. 271). In addition, and consistent with the theoretical tenets of the tripartite model, RISE was also identified as being able to bring about relationship persistence intentions, greater relationship satisfaction, and elevated motivation in relational contexts.

Perhaps paradoxically, and contrary to Lent and Lopez's (2002) assertions, low levels of RISE were also identified as being related to enhanced motivation for the holder of those RISE perceptions. Snyder and Stukas (1999) provided a rationale for such responses and identified that individuals in dyads may actively seek to disconfirm the expectations they believe others have for them. For instance, if one estimates unfavorable RISE beliefs (i.e., the athlete believes that the partner holds low other-efficacy perceptions), behavioral disconfirmation could occur when the athlete becomes motivated to disconfirm the partner's perception (i.e., prove them wrong). Given that diminished RISE beliefs may be related to both enhanced as well as diminished motivation, research is clearly needed to understand what moderating variables may account for such differential outcomes in athletic contexts (e.g., one's status/level of authority in the dyad, one's affective state).

Although the results of this study highlight potential interrelationships among the tripartite efficacy constructs, as well as possible antecedents and consequences, future research is clearly warranted, and a number of avenues are proposed. First of all, research with athlete dyads of varying longevity and competitive levels is needed to assess the utility and generalizability of the tripartite model across dyadic contexts (e.g., youth sports, coach-athlete dyads). Second, although the elite athletes sampled in this study identified various factors that they thought influenced their tripartite efficacy beliefs, experimental research is required to determine if these factors causally precede the abovementioned efficacy constructs and, if so, the strength of influence (i.e., effect sizes). For example, by manipulating the feedback provided to an individual regarding his or her partner's performance, it may be possible to ascertain the extent to which third-party comments and perceptions of the partner's performance impact upon one's other-efficacy perceptions. Third, it is noteworthy that one of the primary sources of selfefficacy identified by Bandura (1997), vicarious experiences, did not emerge as a salient antecedent in this study. Although the elite athletes in this study may not have viewed vicarious experiences (or modeling) as a salient source, it raises the possibility that additional antecedents regarding each of the tripartite constructs may exist beyond those identified in this study. Similarly, despite Lent and Lopez's (2002) theoretical assertions, it is worth noting that RISE and other-efficacy were not reported to be related in the current study. That is, there was a lack of "assumed similarity" in this instance (Kenny \& Acitelli, 2001), whereby athletes did not 
appear to report "I think he's confident in my ability (high RISE) because I'm confident in his ability (high other-efficacy)." In future, it would be interesting to test this relationship (or lack thereof) under experimental conditions. Finally, it would be particularly worthwhile to further examine the negative findings that were observed in relation to positive other-efficacy, as well the enhanced motivation that was found to be associated with low RISE beliefs. One fruitful approach would be to examine the effects of concordance/discordance between self-efficacy, other-efficacy, and RISE within dyads. For instance, this may highlight whether athletes are likely to report dysfunctional relational cognitions when they are more confident in their partner's capabilities than they are in their own.

From an applied perspective, the results of this study suggest a number of implications for athletes, coaches, and sport psychology practitioners. Broadly, the emergence of specific antecedent themes for the tripartite efficacy constructs provides coaches and sport psychology consultants with a preliminary conceptual framework to support the development and maintenance of close relationships within sport. For example, to bolster other-efficacy perceptions, a coach or psychologist may seek to provide positive comments that highlight previous dyadic successes as well as the strengths of the current partner in relation to previous partners. Importantly, given the relationship between other-efficacy and self-efficacy, such interventions may also favorably support athletes' confidence in their own ability. In a similar regard, given the potential for RISE beliefs to not only influence self-efficacy, but also various salient relational outcomes (e.g., relationship persistence intentions), coaches and consultants may choose to work with athletes on the types of verbal and nonverbal behaviors that are used to convey implicit messages to their partners. Specifically, athletes may be encouraged to overtly demonstrate positive verbal support and nonverbal behavior (e.g., display positive body language) to bolster their partner's RISE estimations. Conversely, if athletes are concerned about a specific facet of their partners' capabilities, feedback may be delivered in such a way as to protect the partners' RISE perceptions. For example, an athlete may choose to employ mistake-contingent technical instruction (Smith \& Smoll, 2007) with her partner, while at the same time providing verbal persuasion that reinforces her beliefs in her partner's capabilities to perform the task or skill.

In conclusion, the results of this study make a number of important contributions to the extant sport psychology literature, and extend previous conceptualizations related to personal efficacy beliefs within athletic settings. Specifically, the results provide preliminary support for the contention that self-efficacy, otherefficacy, and RISE may be related to a number of salient task-related (e.g., motivation, performance) and relationship-oriented (e.g., relationship persistence intentions, relationship termination) consequences in elite sport. In addition, the results suggest that a range of antecedents may exist for each of the tripartite efficacy constructs that include perceptions regarding oneself, one's partner, the dyad, and external factors. Future research is clearly needed to ascertain the direction of the theorized relationships (i.e., functional causality); however, the results do provide unique insight into some of the relational cognitions that may substantively influence the quality of close relationships in elite sport. 


\section{References}

Bandura, A. (1982). Self-efficacy mechanism in human agency. The American Psychologist, 37, 122-147.

Bandura, A. (1986). Social foundations of thought and action: A social cognitive theory. Engelwood Cliffs, NJ: Prentice-Hall.

Bandura, A. (1997). Self-efficacy: The exercise of control. New York: Freeman and Company.

Beauchamp, M.R., \& Whinton, L. (2005). Self-efficacy and other efficacy in dyadic relationships: Riding as one in equestrian eventing. Journal of Sport \& Exercise Psychology, 27(2), 245-252.

Berg, B.L. (2007). Qualitative research methods for the social sciences (6th ed.). Boston, MA: Allyn \& Bacon.

Biddle, S.J.H., Markland, D., Gilbourne, D., Chatzisarantis, N.L.D., \& Sparkes, A.C. (2001). Research methods in sport and exercise psychology: Quantitative and qualitative issues. Journal of Sports Sciences, 19, 777-809.

Bogdan, R., \& Taylor, S.J. (1984). Introduction to qualitative research methods. The search for meanings. Toronto: Wiley.

Bonito, J.A. (2002). The analysis of participation in small groups: Methodological and conceptual issues related to interdependence. Small Group Research, 33, 412-438.

Chaiken, S., Liberman, A., \& Eagly, A.H. (1989). Heuristic and systematic processing within and beyond the persuasion context. In J.S. Uleman \& J.A. Bargh (Eds.), Unintended thought (pp. 212-252). New York: Guilford.

Chase, M.A., Feltz, D.L., \& Lirgg, C.D. (2003). Sources of collective and individual efficacy of collegiate athletes. International Journal of Sport Psychology, 1, 180-191.

Creswell, J. (2003). Qualitative inquiry and research design: Choosing among five traditions. Thousand Oaks, CA: Sage.

Gergen, M.M., \& Gergen, K. (2003). Social construction: A reader. London: Sage.

Jackson, B., Beauchamp, M.R., \& Knapp, P. (2007). Relational efficacy beliefs in athlete dyads: An investigation using actor-partner interdependence models. Journal of Sport \& Exercise Psychology, 29, 170-189.

Kenny, D.A., \& Acitelli, L.K. (2001). Accuracy and bias in perceptions of the partner in close relationships. Journal of Personality and Social Psychology, 80, 439-448.

Kenny, D.A., Kashy, D.A., \& Cook, W.L. (2006). Dyadic data analysis. New York: Guilford.

Krippendorff, K. (2004). Content analysis: An introduction to its methodology (2nd ed.). Thousand Oaks, CA: Sage.

Lent, R.W., \& Lopez, F.G. (2002). Cognitive ties that bind: A tripartite view of efficacy beliefs in growth-promoting relationships. Journal of Social and Clinical Psychology, 21, 256-286.

Lincoln, Y.S., \& Guba, E. (1985). Naturalistic inquiry. Beverley Hills, CA: Sage.

Lubker, J.R., Watson, J.C., II, Visek, A.J., \& Geer, J.R. (2005). Physical appearance and the perceived effectiveness of performance enhancement consultants. The Sport Psychologist, 19, 446-458.

Mays, N., \& Pope, C. (1995). Qualitative research: Rigour and qualitative research. British Medical Journal, 311, 109-112.

Merrick, E. (1999). An exploration of quality in qualitative research: Are "reliability" and "validity" relevant? In M. Kopala \& L.A. Suzuki (Eds.), Using qualitative methods in psychology (pp. 25-36). Thousand Oaks, CA: Sage.

Miles, M.B., \& Huberman, A.M. (1990). Qualitative data analysis: A sourcebook of new methods. Newbury Park, CA: Sage. 
Miles, M.B., \& Huberman, A.M. (1994). Qualitative data analysis: An expanded sourcebook (2nd ed.). Thousand Oaks, CA: Sage.

Moritz, S.E., Feltz, D.L., Fahrbach, K.R., \& Mack, D.E. (2000). The relation of self-efficacy measures to sport performance: A meta-analytic review. Research Quarterly for Exercise and Sport, 71, 280-294.

Nordin, S.M., \& Cumming, J. (2005). Professional dancers describe their imagery: Where, when, what, why, and how. The Sport Psychologist, 19, 395-416.

Ponterotto, J.G. (2005). Qualitative research in counseling psychology: A primer on research paradigms and philosophy of science. Journal of Counseling Psychology, $52,126-136$.

Schwandt, T.A. (2000). Three epistemological stances for qualitative enquiry: Interpretivism, hermeneutics, and social constructionism. In N. K. Denzin \& Y. S. Lincoln (2000). Handbook of qualitative research (2nd ed., pp. 189-213). Thousand Oaks, CA: Sage.

Smith, R.E., \& Smoll, F.L. (2007). Social cognitive approach to coaching behaviors. In S. Jowett \& D. Lavallee (Eds.), Social psychology in sport (pp. 75-90). Champaign, IL: Human Kinetics.

Snyder, M., \& Stukas, A.A. (1999). Interpersonal processes: The interplay of cognitive, motivational, and behavioral activities in social interaction. Annual Review of Psychology, 50, 273-303.

Stiles, W.B. (1993). Quality control in qualitative research. Clinical Psychology Review, 13, 593-618.

Strauss, A., \& Corbin, J. (1998). Basics of qualitative research: Techniques and procedures for developing grounded theory (2nd ed.). Thousand Oaks: Sage.

Tesch, R. (1990). Qualitative research analysis types and software tools. New York: Falmer Press.

Wickwire, T.L., Bloom, G.A., \& Loughead, T.M. (2004). The environment, structure, and interaction process of elite same-sex dyadic sport teams. The Sport Psychologist, 18, 381-396.

Manuscript submitted: June 18, 2007

Revision accepted: April 13, 2008 